\title{
ERRATUM OPEN
}

\section{Erratum: Non-quasiparticle transport and resistivity saturation: a view from the large-N limit}

Yochai Werman ${ }^{1}$, Steven A. Kivelson ${ }^{2}$ and Erez Berg ${ }^{1}$

npj Quantum Materials (2017)2:58; doi:10.1038/s41535-017-0060-5

Erratum to: npj Quantum Materials (2017); doi:10.1038/s41535017-0009-8; Published 08 February 2017

This paper contained an incorrect grant code in the Acknowledgements section. This has now been replaced with the correct code.

This error has now been corrected in the HTML and PDF versions of this article.

Open Access This article is licensed under a Creative Commons Attribution 4.0 International License, which permits use, sharing, adaptation, distribution and reproduction in any medium or format, as long as you give appropriate credit to the original author(s) and the source, provide a link to the Creative Commons license, and indicate if changes were made. The images or other third party material in this article are included in the article's Creative Commons license, unless indicated otherwise in a credit line to the material. If material is not included in the article's Creative Commons license and your intended use is not permitted by statutory regulation or exceeds the permitted use, you will need to obtain permission directly from the copyright holder. To view a copy of this license, visit http://creativecommons. org/licenses/by/4.0/.

(c) The Author(s) 2017

${ }^{1}$ Department of Condensed Matter Physics, The Weizmann Institute of Science, Rehovot 76100, Israel and ${ }^{2}$ Department of Physics, Stanford University, Stanford, CA 94305, USA Correspondence: Yochai Werman (yochai.werman@weizmann.ac.il)

Published online: 20 October 2017 